\title{
Drug utilisation study in surgery outpatient department at Ashwini Rural Medical College, Kumbhari, Solapur
}

\author{
Pramod P. Bhalerao, Chandrakant S. Waghmare*
}

Department of Pharmacology, Ashwini Rural Medical College and Research Centre, Kumbhari, Solapur, Maharashtra, India

Received: 27 July 2019

Revised: 09 August 2019

Accepted: 13 August 2019

*Correspondence to:

Dr. Chandrakant S. Waghmare,

Email: drckant@gmail.com

Copyright: (C) the author(s), publisher and licensee Medip Academy. This is an openaccess article distributed under the terms of the Creative Commons Attribution NonCommercial License, which permits unrestricted noncommercial use, distribution, and reproduction in any medium, provided the original work is properly cited.

\begin{abstract}
Background: Drug utilization studies should be regularly conducted to increase therapeutic efficacy, decrease adverse effects and provide feedback to prescribers to promote the rational use of drugs. Systematic audit of prescriptions in Surgery Outpatient Department are very few in India. This study was conducted to study drug prescription pattern in Surgery Outpatient Department (OPD) in Ashwini Rural Medical College, Kumbhari.

Methods: Six hundred prescriptions were screened and analyzed as per the study parameters at Surgery OPD of Ashwini Rural Medical College, Kumbhari. Study parameters like demographic profile of the patient like age, sex and diagnosis were recorded. Also groups of drugs commonly prescribed, number of drugs per patient, drug profile and drawbacks of prescription if any were recorded and analyzed. The percentage of the drugs prescribed by generic names and from the essential drug list was calculated.

Results: Most common group of drugs prescribed by physicians were drugs for peptic ulcer (27.26\%), followed by antimicrobials (20.89\%). The average number of drugs prescribed per patient was 2.98. Drug prescription by generic name was low $(8.82 \%)$. The incidence of polypharmacy was common occurrence and some prescriptions had small drawbacks like absence of diagnosis, absence of doctor's signature, absence of patient age etc.

Conclusions: Prescribing by generic name and from the essential drug lists should be encouraged. Training sessions on the correct method of writing prescriptions are needed.
\end{abstract}

Keywords: Drug utilization, Prescribing patterns, WHO drug use indicators

\section{INTRODUCTION}

Drug utilization has been defined by the WHO as the study of the marketing, distribution, prescription and use of drugs in a society with special emphasis on the resulting medical, social and economic consequences. ${ }^{1}$ The aim of Drug utilization study is to facilitate the rational use of drugs. The rational drug use implies the prescription of the drug in an optimal dose on right indication, at an affordable price. It is important to realize that inappropriate use of drugs represent a potential hazard to the patient and an unnecessary expense. ${ }^{2}$
Irrational drug combinations, banned drugs and withdrawn drugs are still being prescribed by physicians. ${ }^{3}$ Irrational prescription of drugs is of common occurrence in clinical practice; the important reason being the lack of knowledge about the drug and unethical promotion of drugs. Monitoring of prescription and drug utilization patterns should be done periodically to increase the therapeutic efficacy, decrease the adverse effects and provide feedback to the prescriber to ensure rational use of medicines. ${ }^{4}$

Studies on drug prescribing patterns and systematic audit of prescriptions among surgery outpatient department are 
very few in hospitals of India; hence, this study was carried out.

The objective of this study was to evaluate the prescribing and drug utilization pattern in surgery outpatient department of ARMCH, Kumbhari, Solapur (Maharashtra) with an objective of studying:

- Total number of prescriptions,

- Average number of drugs per prescription,

- Prescribing frequency of most commonly prescribed drugs,

- Prescribing frequency of different dosage forms,

- Prescribing frequency of fixed - dose combinations,

- Prescribing by trade/generic name,

- Percentage of drugs prescribed from WHO EDL (essential drug list)/national list of essential medicines.

\section{METHODS}

Study design: Cross-sectional study.

Study place: A tertiary care hospital situated in the rural area of Solapur district (ARMCH, Kumbhari).

Study period: 6 months (January 2019- June 2019).

\section{Inclusion criteria}

Inclusion criteria were patients attending surgery OPD of the Institute.

\section{Exclusion criteria}

Exclusion criteria were emergency patients coming to the surgery OPD, patients who were referred for admission.

\section{Procedure}

Prescriptions of the patients attending the Surgery outpatient department at ARMCH, Kumbhari were selected. Prescriptions were scanned by mobile and all scanned prescriptions were examined with reference to study parameters. Accordingly, a sample of six hundred $(n=600)$ prescriptions of either sex were randomly selected for prescription pattern analysis. Collected prescriptions were analyzed based on the objective of the study. The age and sex of the patients, groups of drugs commonly prescribed, number of drugs per patient, drug profile and drawbacks of prescription if any were recorded and analyzed. The percentage of drugs prescribed by generic names and from the Essential Drug list of India was calculated. The percentage of drugs, which were fixed dose combinations (FDCs), was determined.

\section{Ethical approval}

The study was approved by the Institutional Ethics Committee.

\section{Statistical analysis}

The data was entered in MS Excel and the data was presented in frequency and percentage.

\section{RESULTS}

Data of patients $(n=600)$ was analyzed according to the study parameters. Total number of drugs prescribed in these patients was 1790. Therefore, average number of drugs per patient was 2.98. Most common drugs prescribed were drugs for peptic ulcer $(27.26 \%)$ followed by antimicrobials $(20.89 \%)$ (Table 1$)$. The most frequently prescribed drug for peptic ulcer was ranitidine $(11.28 \%)$. The most frequently prescribed antimicrobial was a fixed dose combination of ofloxacin+ornidazole $(4.13 \%)$. The most frequently prescribed analgesic was a fixed dose combination of diclofenac+paracetamol+ serratopeptidase $(9.1 \%)$.

Table 1: Common categories of drugs prescribed in surgery OPD $(n=1790)$.

\begin{tabular}{|lll|}
\hline Category of drugs & Total drugs & $\%$ \\
\hline Drugs for peptic ulcer & 488 & 27.26 \\
\hline Antimicrobials & 374 & 20.89 \\
\hline Analgesics & 284 & 15.86 \\
\hline Antispasmodic & 169 & 9.44 \\
\hline Multivitamin/multiminerals & 143 & 7.99 \\
\hline Miscellaneous drugs & 134 & 7.49 \\
\hline Laxatives & 88 & 4.91 \\
\hline Ayurveda drugs & 63 & 3.51 \\
\hline Local anesthetics & 47 & 2.62 \\
\hline
\end{tabular}

The incidence of polypharmacy was also common occurrence. Number of prescriptions containing 3 drugs (29.66\%) was the commonest occurrence (Table 2).

Table 2: Number of drugs prescribed per prescription $(n=600)$.

\begin{tabular}{|lll|}
\hline $\begin{array}{l}\text { Prescription containing } \\
\text { number of drugs }\end{array}$ & $\begin{array}{l}\text { Total } \\
\text { prescriptions }\end{array}$ & $\%$ \\
\hline 1 drug & 72 & 12.00 \\
\hline 2 drugs & 128 & 21.33 \\
\hline 3 drugs & 178 & 29.66 \\
\hline 4 drugs & 152 & 25.33 \\
\hline 5 drugs & 54 & 09.00 \\
\hline 6 drugs & 16 & 02.66 \\
\hline
\end{tabular}

Dosage forms used were mostly oral $92.74 \%$. Topical forms were only $6.14 \%$ and injectable were only $1.12 \%$ (Table 3). 
Table 3: Dosage forms prescribed out of total drugs $(\mathbf{n}=1790)$.

\begin{tabular}{|lll|}
\hline Dosage forms & $\begin{array}{l}\text { Total drugs } \\
\text { prescribed }\end{array}$ & $\%$ \\
\hline Oral & 1660 & 92.74 \\
\hline Topical & 110 & 06.14 \\
\hline Injectable & 20 & 01.12 \\
\hline
\end{tabular}

Only $8.82 \%$ of the drugs were prescribed by generic name (Table 4).

Table 4: Drug prescription by generic and brand names $(n=1790)$.

\begin{tabular}{|lll|}
\hline Drug prescription & Total drugs & $\%$ \\
\hline $\begin{array}{l}\text { Drugs prescribed by } \\
\text { generic name }\end{array}$ & 158 & 08.82 \\
\hline $\begin{array}{l}\text { Drugs prescribed by } \\
\text { brand name }\end{array}$ & 1632 & 91.18 \\
\hline
\end{tabular}

Various problems were also encountered in these prescriptions. Doctors sign was absent in $10.50 \%$ of the prescriptions. Patient age was not written in $56.00 \%$ of the prescriptions. Patient sex was not written in $57.16 \%$ of the prescriptions. Patients address was not written in $100.00 \%$ of the prescriptions. Diagnosis was not written in $100.00 \%$ of the prescriptions (Table 5).

Table 5: Prescription related parameters $(n=600)$.

\begin{tabular}{|lll|}
\hline $\begin{array}{l}\text { Prescription related } \\
\text { parameters }\end{array}$ & $\begin{array}{l}\text { Total } \\
\text { prescriptions }\end{array}$ & $\%$ \\
\hline $\begin{array}{l}\text { Doctors name not } \\
\text { written }\end{array}$ & 35 & 05.83 \\
\hline Doctors sign absent & 63 & 10.50 \\
\hline $\begin{array}{l}\text { Doctor registration no. } \\
\text { absent }\end{array}$ & 42 & 07.00 \\
\hline $\begin{array}{l}\text { Patient name not } \\
\text { written }\end{array}$ & Zero & 0 \\
\hline Patient age not written & 336 & 56.00 \\
\hline Patient sex not written & 343 & 57.16 \\
\hline $\begin{array}{l}\text { Patient address not } \\
\text { written }\end{array}$ & 600 & 100.00 \\
\hline Diagnosis not written & 600 & 100.00 \\
\hline Date not written & 180 & 30.00 \\
\hline
\end{tabular}

Dose of the drug was not written in 1351/1790 of the drugs $(75.47 \%)$. Duration of treatment was not written in $108 / 1790$ of the drugs $(6.03 \%)$. Drugs prescribed from National List of Essential Medicines (NLEM) were 1040/1790 (58.10\%). Out of the total 1790 formulations prescribed, $990(55.30 \%)$ were fixed dose combinations.

\section{DISCUSSION}

The present study was conducted to study drug utilization pattern in surgery outpatient department of Ashwini Rural
Medical College, Kumbhari, Maharashtra. The most common groups of drugs were Drugs for Peptic Ulcer and Antimicrobials.

An injection was prescribed in $1.12 \%$ of encounters. The percentage is less than that reported by Shankar et al $(5.21 \%) .{ }^{5}$ Excessive use of injections adds to the cost of sterilization and nursing resources and increases problems such as pain and sepsis.

Average number of drugs per encounter in the present study was found to be 2.98 which are higher than the study by Banerjee et al. which mentioned that 2.58 drugs were prescribed per patient. ${ }^{6}$ Polypharmacy increases the cost of therapy unless the prescribed drugs are genuinely necessary. Also, it decreases compliance of the patient so the drugs should be used judiciously. Polypharmacy also increases the chances of drug-drug interactions.

Percentage of drug prescribed by generic name, in present study was $8.82 \%$. In a study conducted by Sukhlecha et al, $19.6 \%$ drugs were prescribed with a generic name, which is much higher than what our study reported. ${ }^{7}$ Prescribing by generic name can reduce the cost incurred on drugs and the risk of medication errors. Vigorous promotional activities by pharmaceutical companies have been found to increase the number of prescriptions with brand names.

Around $55.30 \%$ drugs prescribed were FDCs which is higher than that of the study conducted by Rehan et al $(45 \%) .{ }^{8}$ The advantage of FDCs is the lesser number of drug doses to be taken by the patient and an improved compliance. However, the FDC may not contain the required amount of individual drugs. The combination may not be synergistic and it would only add to the cost of the therapy.

Essential medicines are those that satisfy the priority health care needs of the population. They are intended to be available at all times, in adequate amounts, in appropriate dosage forms, with assured quality, with adequate information, and at a price the individual and community can afford. ${ }^{9}$ Analysis of Essential Medicines was done with reference to Tripathi. ${ }^{10}$ In the present study, results showed that the percentage of drugs prescribed from essential drug list was (58.10\%), which was low as compared to study done by Biswas et al. ${ }^{11}$ Prescribing of essential drugs should be encouraged. Prescription from the essential drug list gives maximum benefit from limited resource, promotes rational use of drugs, assists the development of standard treatment protocol and rational prescribing policies and also increases economic advantages like lowering the cost of therapy. ${ }^{12}$ Efforts should be made to develop a hospital formulary. 


\section{CONCLUSION}

There is a clear need for the development of prescribing guidelines and educational initiatives to encourage the rational and appropriate use of drugs in surgery OPD. Clinicians need to comply with hospital guidelines, especially on antimicrobial prescribing. There should be an antimicrobial policy for the hospital. Efforts must be made to encourage prescribing by generic names and to increase prescribing from the essential drug lists. Polypharmacy should be discouraged because it is an economic burden to the nation and makes health care unaffordable to the poor. The use of FDCs that are not approved by the WHO should be discouraged. Continuing medical education workshops should be organized for clinicians. The importance of legible handwriting, recording of age and sex of patient, the outdoor or indoor number, diagnosis and dose, frequency and duration of prescribing of various drugs should be emphasized in these workshops. Studies on prescribing in various outpatient departments over a longer time period should be carried out.

\section{ACKNOWLEDGEMENTS}

The authors are grateful to the staff of Surgery department $\mathrm{ARMCH}$, Kumbhari for providing facilities to carry out this project successfully.

\section{Funding: No funding sources}

Conflict of interest: None declared

Ethical approval: The study was approved by the Institutional Ethics Committee

\section{REFERENCES}

1. Pradhan SC, Shewade DG, Shashindran CH, Bapna JS. Drug utilization studies. National Med J India. 1988;1(4):185-9.

2. Shalini S, Ravichandran V, Mohanty BK, Dhanaraj SK, Saraswathi R. Drug utilization studies-An overview. Int J Pharma Sci Nanotechnol. 2010;31:803-10.
3. Salman MT, Akram MF, Rahman S, Khan FA, Haseen MA, Khan SW. Drug prescribing pattern in surgical wards of a teaching hospital in North India. Indian J Pract Doctor. 2008;5(2):5-6.

4. Krishnaswamy K, Dinesh Kumar B, Radhaiah G. A drug survey- precepts and practices. Eur J Clin Pharmacol. 1985;29:363-70.

5. Shankar RP, Pranab KS, Upadhyay DK, Dubey AK, Subish P. Drug utilization among surgical outpatients. Hospital. 2004;31.

6. Banerjee I, Bhadury T. Prescribing pattern of interns in a primary health center in India. J Basic Clin Pharm. 2014;5(2):40.

7. Sukhlecha AG, Vaya S, Parmar GG, Chavda KD. Pattern of drug utilization in surgical outpatient department of a teaching hospital located in western India. Int J Med Sci Public Health. 2015;4(9):1291-7.

8. Rehan HS, Singh C, Tripathi CD, Kela AK. Study of drug utilization pattern in dental OPD at a tertiary care teaching hospital. Indian $\mathbf{J}$ Dent Res 2001;12(1):51-6.

9. WHO Expert Committee. The use of essential drugs. World Health Organ Technical Report Series. 2000;895:1-61.

10. Appendix -1. List of Essential medicine. In: Tripathi KD 7th Ed. Jaypee Brothers. Reprint; 2014: 957-961.

11. Biswas NR, Biswas RS, Pal PS, Jain SK, Malhotra SP, Gupta A, et al. Patterns of prescriptions and drug use in two tertiary hospitals in Delhi. Indian J Physiol Pharmacol. 2000;44(1):109-12.

12. Chandra S, Khan IN, Mateenudin M, Chandrakapure A, Maaz S, Mubin F. Drug utilization study in OPD of a tertiary care hospital in a rural area of Jalna, Maharashtra, India by using WHO prescribing indicators. Int J Basic Clin Pharmacol. 2018;7(1):558.

Cite this article as: Bhalerao PP, Waghmare CS. Drug utilisation study in surgery outpatient department at Ashwini Rural Medical College, Kumbhari, Solapur. Int J Basic Clin Pharmacol 2019;8:1966-9. 